\title{
Approaches Made by University Libraries in Support of Inclusive Education: A Case of Kenyatta University Library, Nairobi- Kenya
}

\author{
Zipporah Gichuhi $^{1} \quad$ Mathew Karia $^{2} \quad$ Francis Kirimi $^{3}$ \\ 1.Department of Library and Information Science, Kenyatta University, P.O Box 43844, 00100, Kenya \\ 2.Department of Early Childhood and Special Education Kenyatta University,Nairobi,00100,Kenya \\ 3.Department of Educational Foundations. Kenyatta University, Nairobi, 00100, Kenya
}

\begin{abstract}
Education sector is undergoing major transformations, rationalization, restructuring and redefinition. As an integral part of the university education, university libraries should be instrumental in responding to the changes taking place in university education and play a key role in this process. Although Inclusive Education is a new paradigm shift in the Education sector the provision of information and information services to all users has always been a cardinal principle of librarianship. The study sought to explore the approaches taken by Kenyatta University, post-modern library in support of inclusive education. Descriptive survey design was used. Findings revealed that the library structure was accessible and comfortable. A section on ground floor, well serviced and equipped was dedicated for users with disabilities. Information resources in different formants were available as well as varied Assistive technologies. A selected number of librarians had competencies in use of Assistive technologies. The approaches made by the library were rated as good. The ability to identify users with different forms of disabilities and changing technologies remain major challenges. The study recommends greater collaboration with other stakeholders in identification of special needs users, increase budget and train or deploys more staff in provision of various specialized information services.
\end{abstract}

Keywords: University libraries, Special needs users, Inclusive Education

DOI: $10.7176 / \mathrm{JEP} / 12-15-06$

Publication date:May $31^{\text {st }} 2021$

\section{Introduction}

Education sector is undergoing major transformations, rationalization, restructuring and redefinition in order to respond to the many socio-economic developments and educational needs of the modern society (Virkus,2004). As an integral part of the university education, the university library is affected by the changes taking place in the university. To enable universities, meet their mandate and remain competitive, university libraries should be instrumental in responding to the changes taking place in university education and play a key role in this process. One such change is the process of mainstreaming children with disabilities in regular classrooms or schools.

The prime objective of all libraries is to support the information needs of their diverse publics by facilitating identification, organization, retrieval, access and dissemination of information. Libraries must therefore ensure that their services are inclusive and the environment welcoming and conducive to all users.

\section{Inclusive Education}

Inclusive Education is a new paradigm shift in the Education sector that calls for integration in learning environments to enhance inclusion. It is a system of Education that aims at providing equitable and quality education services to all children irrespective of different learning needs, physical, emotional or other forms of disabilities without any form of discrimination.

Miller (2001) is of the view that Inclusive Education (IE) is a total reformation of education system in terms of pedagogy and curriculum. UNESCO-IBE, (2008) defined Inclusive Education "as an ongoing process aimed at offering quality education services for all while respecting diversity and the different needs and abilities, characteristics and learning expectations of users and communities eliminating all forms of discrimination" (p.3). Gianino, (2012) regards Inclusive Education as the process of providing equitable and quality education to all children without any form of discrimination. Suleymanov (2015) for his part, view Inclusive Education as a process of educating learners with special educational needs in regular educational settings.

Thomas and Vaughan (2004) postulate that the target of IE is to value all children as equal for education in order to be able to take full participation in social life of society. The European Agency for Special Needs and Inclusive Education (2015), asserts that the ultimate vision for Inclusive Education systems is "to ensure that all learners of any age are provided with meaningful, high quality educational opportunities in their local community, alongside their friends and peers' (European Agency, 2015).

The foundation of Inclusive Education dates back to the Declaration of Human Rights (1948) which emphasizes that everyone has a right to Education. The World Declaration on Education for All (EFA) in 
Jomtien, Thailand (1990) went ahead do define principles of IE as the provision of universal access to education to schools for everybody and the promotion of equity. The World Education forum, held in Dakar (2000) reaffirmed previous deliberations by emphasizing priority on the need for equity of services and practices to groups of children who are vulnerable and disadvantaged. The UN Convention, (2006) on the Rights of Persons with disabilities, Article 7, decisively declared that parties shall take all necessary measures to ensure the full enjoyment by children with disabilities of all human rights. Similarly, UN (2015) SDG's (No 4) lay emphasis on vulnerable persons being provided with vocational training for full realization of vision 2030. Similarly, experts attending the UNESCO-IBE meeting in Paris in 2014 agreed that education is a human right and a strategy to prepare all leaners for a 21st century globalized society. The Constitution of Kenya (2010) and Basic Education Act (2013) add weight to above matter while holding that all children have a right of admission to any public school without any form of discrimination. All these global and national initiatives point to one fact that education and all other services and programs associated with it are expected to be accessible and inclusive.

To support inclusive education, university libraries should deliberately make their information services inclusive and accessible. To play their role in support of university mission, university libraries should put in place a range of initiatives to support the realization of this noble process. This means that library facilities, environment, human resources, equipment, services, programs, collections and technology should be designed in ways in which all people regardless of their ability have an opportunity to access, participate in and use them. University libraries should ensure that they have a clear understanding of the composition of their users and their diverse information needs timeously so as to plan their specific information services based on a logic of diversity instead of homogeneity.

Inclusive and accessible library services mean the provision of quality and equitable information services, with quality instructions, interventions and support to all users without any form of discrimination. The objective is to ensure all library users are provided with meaningful, high quality library and information services alongside their peers without any form of discrimination.

The greatest challenge in the provision of inclusive library services to all, is due to diversity of users with special needs. Users with special needs vary across a wide range of physical, learning and emotional disabilities to include visual impairment, hearing impairment, speech and/or language impairment, emotional disturbance, cognitive development delays including learning disabilities, Autism, orthopaedic impairment, musculoskeletal impairment and traumatic brain injury among others.

Despite the challenge, accessibility and inclusion is the essence of all library's existence and university librarians must play a major role in facilitating the full participation of people including those with disabilities. In this regard, the authors sought to establish the approaches adopted by the Post-Modern Library of Kenyatta University in the design of library, equipment, provision of materials, human resources, services and programs towards furtherance and success of Inclusive Education. Kenyatta University, Kenya, like other universities enrol students with special needs and integrates them with other learners. It is of crucial importance therefore that the university library provides accessible and inclusive information resources and services to all types of learners to meet their information needs.

\section{Objectives}

The study sought to:

1) Determine type of special needs users served by the university library

2) Determine types of facilities, programs, services, and resources the university library provides to facilitate physical and intellectual access to resources to users with special needs,

3) Explore the feelings and experiences of users with special needs regarding the services provided by KU postmodern library,

4) Determine skills competency of librarians to better support users with special needs,

5) Determine ways of improving library services provided to users with special needs.

\subsection{Methodology}

Descriptive research design was used. A target population of students with disabilities, Special Needs Education lecturers and librarians were sampled. Random sampling technique was used to select students and lectures from Special Needs department. Purposive sampling was used to select library staff. The data collection tools ware structured questionnaires with both open and closed ended questions and interviews. Data was analyzed thematically guided by research objectives.

\subsection{Results}

\subsection{Type of Special Needs Users}

As a starting point to establishing the approaches adopted by KU Post-modern library in support of Inclusive Education, it was necessary to establish types of special needs users served. Findings revealed that KU has a host 
of students and lectures with special needs and the library clearly as per its mandate serves them all. The findings are tabulated in Fig.1.0 below. Users with physical impairment (24\%), visual impairment (21\%) and hearing impairment (18\%) were cited by most informants.

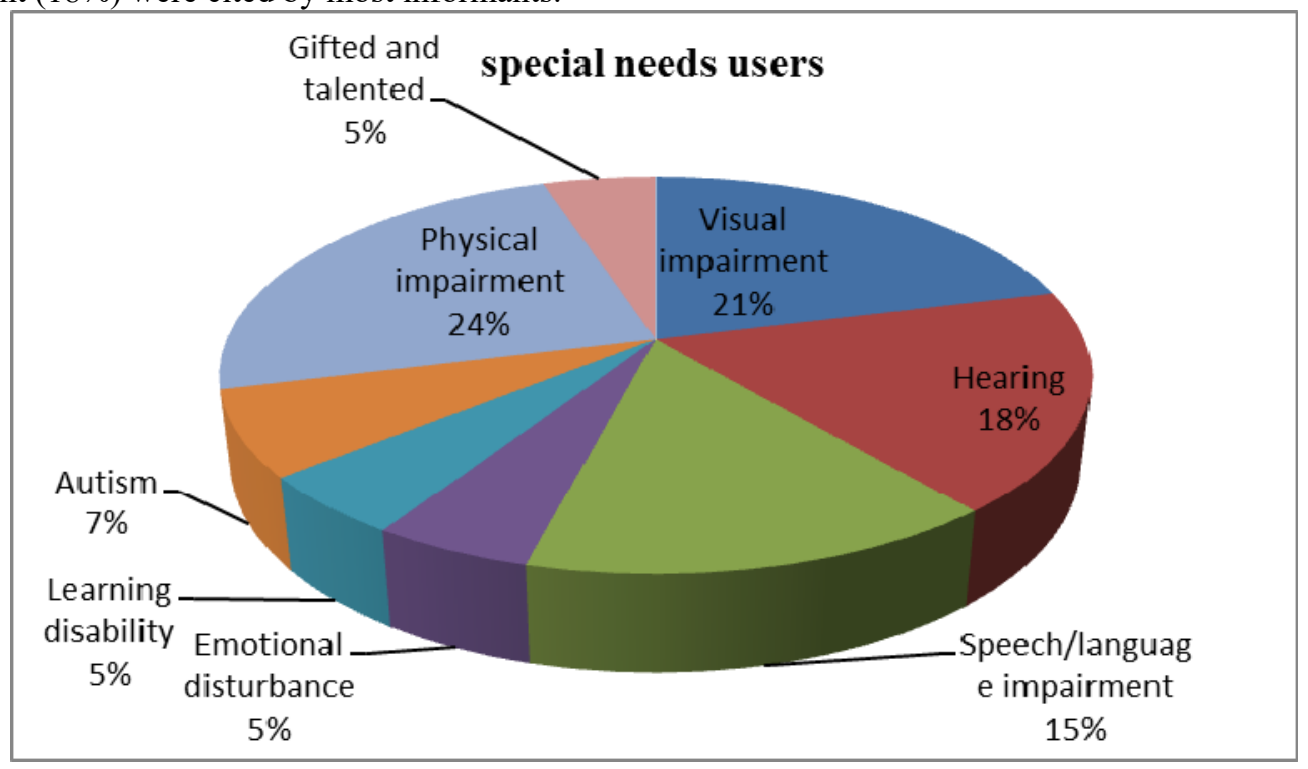

Figure 1.0 Type of disability

\subsection{Facilities/Services for Special Need Users}

Two key principles for librarianship advocate that every user his book and every book its user. In other words, libraries from their very beginning were proponents of inclusive and accessible library services. In this regard, the library structure, information infrastructure and services should be accessible to all users irrespective of condition. The question at hand was to establish whether this has continued to be the case in the midst of a technologically changed world. The results revealed that the PML design facilitate accessibility to resources and allow good maneuverability within it even for users with disability (100\%). Indeed (96\%) of the informants reported that the library facility has adequate room for users on wheelchairs.

Findings from a question put to qualify that the library was indeed supporting Inclusive Education through accessible library resources revealed that the PML has a dedicated section on ground floor for users with disabilities and various learning facilities were provided for users with special needs as reflected in Figure 1.1 below.

\section{Learning facilities provided to users}

Assistive technology is available in many varieties

Internet is accessible to persons with disabilities

Signage is encoded conspicuously in more than one mode to be accessible to a large number of...

Library is wheelchair accessible

Counters and workspaces that accommodate student seated in wheelchairs.

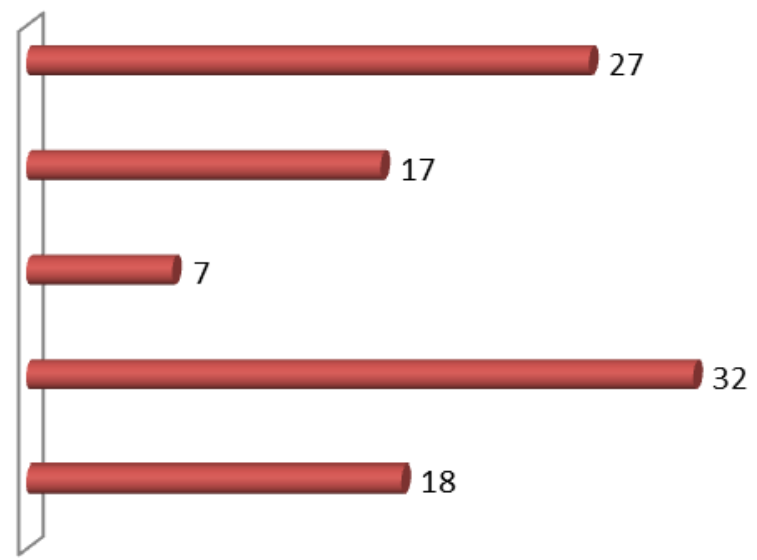

Figure 1.1 Learning facilities provided for users

Adequacy and accessibility of quality information resources are critical components of a viable library service. The findings revealed that the PML has a variety of information resources in different formats stocked in the Library including braille, e-books, talking books, Audio, books in large prints among others. In addition, $92 \%$ of the informants alluded that PML stock resources that meet the needs of special need users. Interview 
informants were of the same view as they said that acquisition librarian stressed on accessibility of materials to all users as a factor they considered at acquisition. Figure 1.2 captures the type of information formats stocked for use by special users.

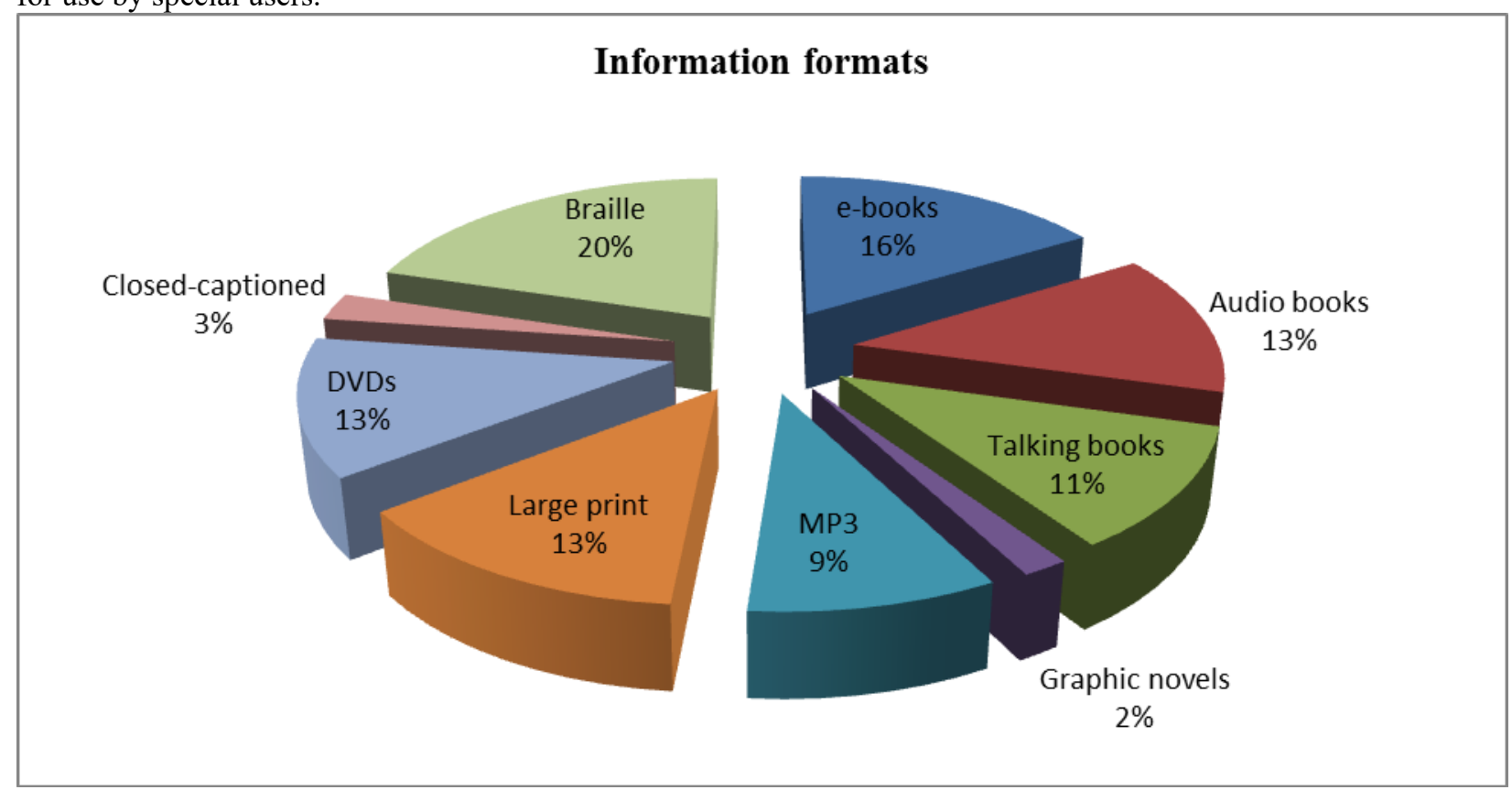

\section{Figure 1.2 Information formats}

As pointed out in the literature reviewed, a real challenge exists in provision of information services to this cadre of users due to their varied nature of disabilities. This concern translates to the need to acquire several types of assistive technologies and the cost implications are huge. The informants revealed that PML has varied Assistive Technologies for use by special needs users. Some of these technologies include screen readers, headsets with microphones, large screen monitors, optical scanners, and embossers among others. Fig 1.4 displays these findings most vividly.

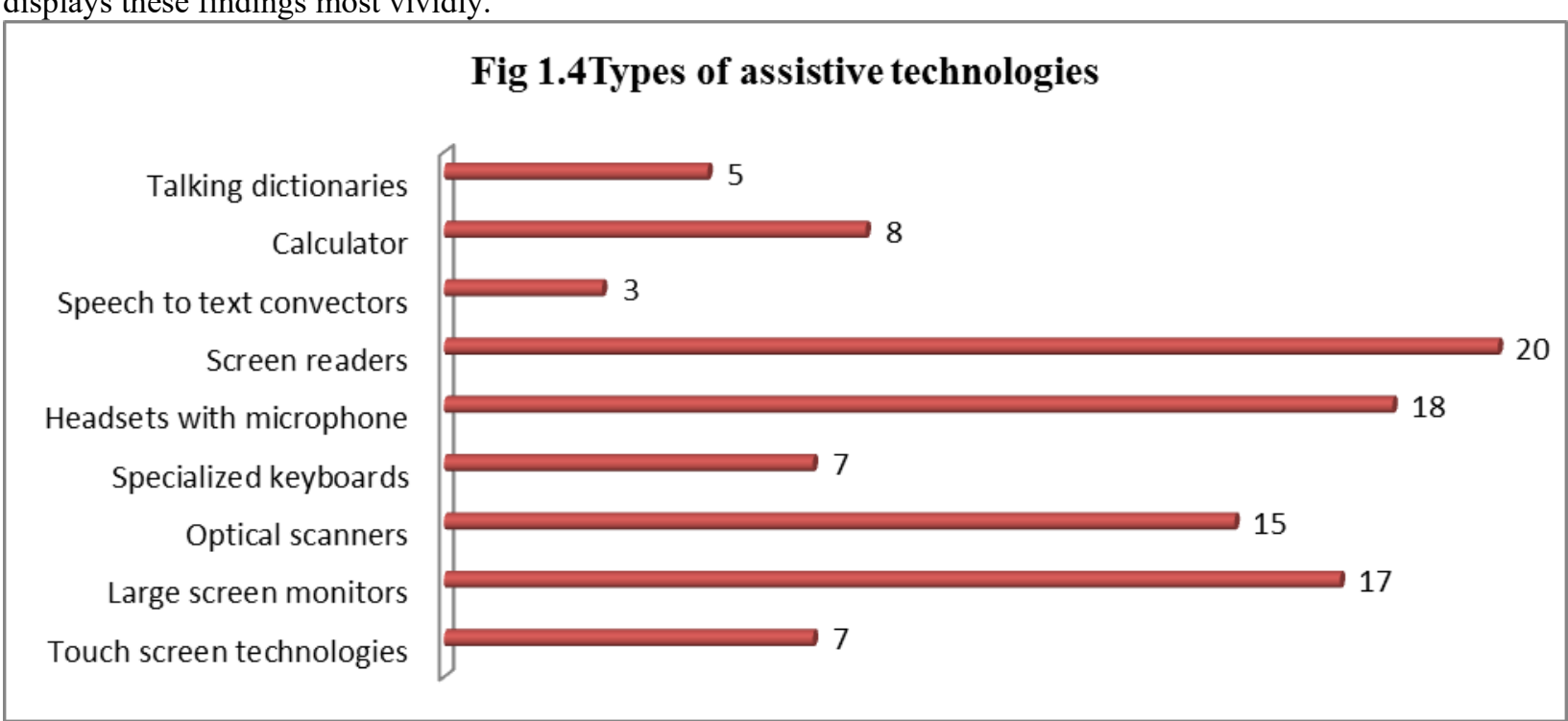

Fig 1.4 Types of assistive technologies

The PML, has installed software (JAWS \&NVDA) that enable the visually impaired to search or listen to information from the internet. In addition, the library reserves spacious parking for users with disabilities along with a pick up and drop off zones. In Kenyatta University, users with disabilities are chauffeured in special vans from one point of university to the other and this enhances accessibility to library services and resources.

\subsection{Skills and Competence}

A crucial requirement for libraries is to ensure that information is made available to all including those with disabilities. In an environment where inclusive education is embraced, and Information Technology has 
permeated information retrieval and dissemination, the librarians require competency in the use of Assistive Technologies available for the special needs' users. The majority $(83 \%)$ of library staff informants reported that they were proficient in the use of Assistive Technologies though not experts. Most $(53 \%)$ of the staff rated themselves as average and $27 \%$ rated themselves as good. Only a small percentage (20\%) rated themselves as experts in this regard. The Special Needs Education (SNE) department lectures interviewed acknowledged they were good in use of Assistive Technologies. Figure 1.5 portrays these findings vividly.

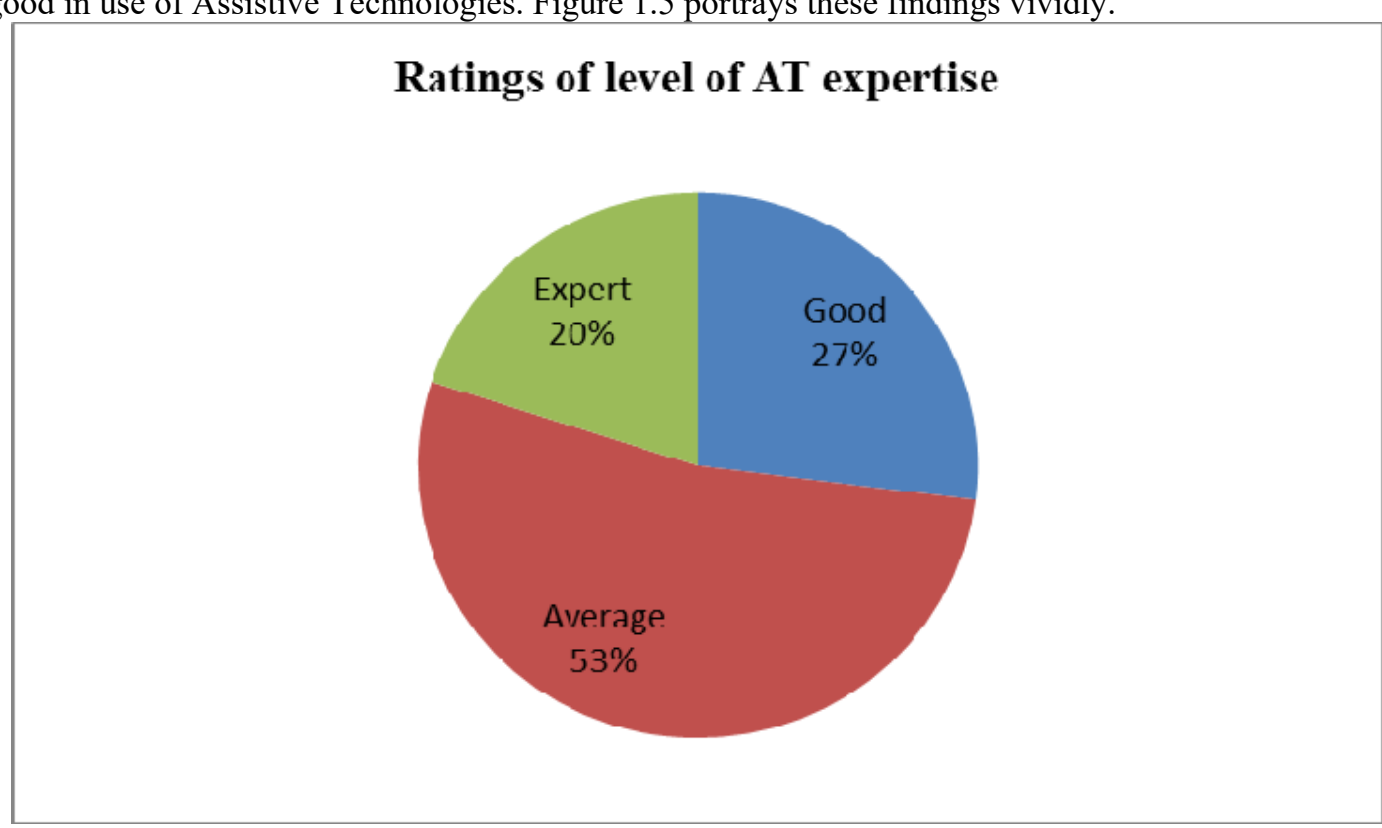

Figure 1.5 Ratings of the level of AT expertise by library staff

An attempt to establish who acquires AT for students revealed the library has the sole mandate to do so. Indeed $67 \%$ of library staff informants pointed to the university librarian while $33 \%$ pointed to the SNE section of the library as in charge of acquisition. The SNE lecturers (100\%) said that the chief librarian acquires AT for students with special needs. SNE lecturers (100\%) said they were not involved/consulted about AT acquisition and implementation. A big percentage of library informants $(67 \%)$ reported they were not involved/consulted about $\mathrm{AT}$ acquisition and implementation.

A question that sought to find out whether AT training was integrated in the university curriculum established that the library staff informants were divided right in the middle as $40 \%$ affirmed while another $40 \%$ said it was not integrated. A small minority $20 \%$ said they could not confirm either way. SNE lecturers (100\%) said that AT training should be integrated into the curriculum.

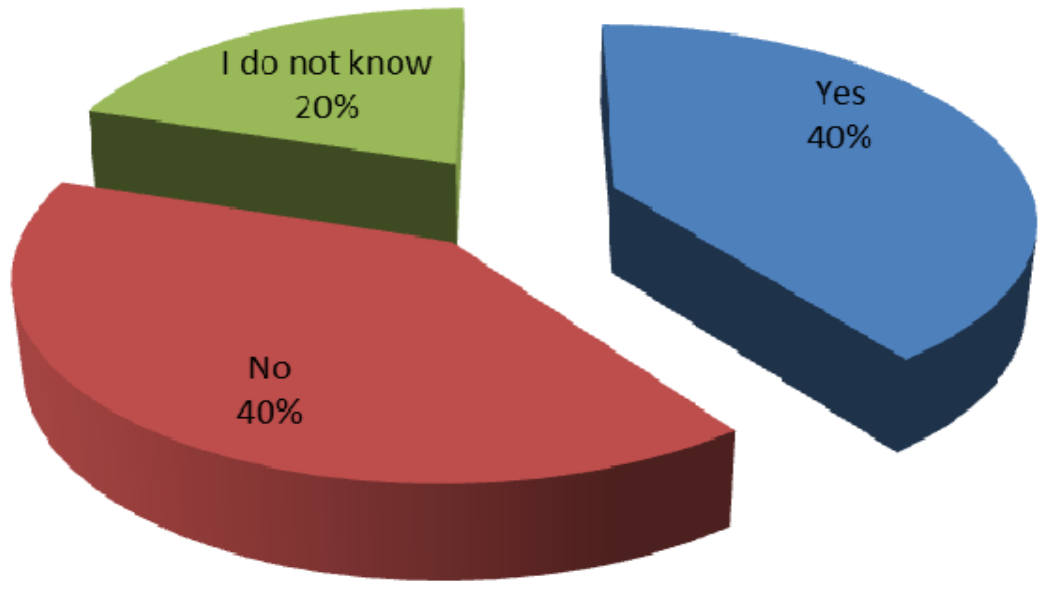

Fig 1.6 AT training intergrated into the curriculum

As a strategy to impart knowledge to others $86 \%$ of the library informants revealed they were involved in 
provision of AT training to library staff. SNE lecturers (100\%) said they were also involved in provision of AT training to library staff. A big percentage $(67 \%)$ of the library informants said they are trained to address and meet the diverse information needs of patrons with special needs while $33 \%$ said they were not trained to address diverse information of patrons with special needs. A response from an interview informant qualified this statement by saying that the library has some staff trained to carter for some specialized special needs users.

Majority of library informants $(93 \%)$ revealed that the library has a budget for the acquisition of materials and other resources for students with disabilities with $92 \%$ of the same informants acknowledging that the acquired library resources meet the needs of special needs users. The library building was accredited (92\%) as being a comfortable place where all students feel welcome to access information and participate meaningfully. Library approaches in support of inclusive education were rated as good (50\%), very good (42\%) and average $(8 \%)$. Fig 1.7 represents these findings.
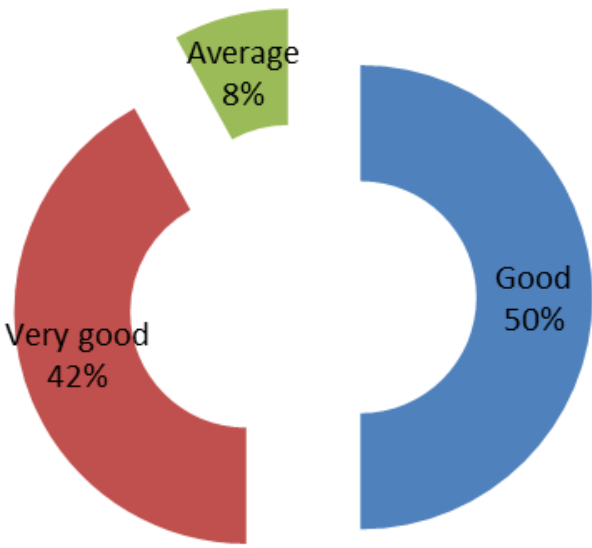

Figure 1.7 Rating of library in supporting inclusive education

Some of the challenges that the library is facing in the provision of inclusive and accessible information services for users with special needs are tabulated in Figure 1.8

Multiplicity of complex multiple disabilities

Insufficient pedagogical knowledge

Insufficient straining in technologies

Insufficient leadership

Insufficient advocacy

Insufficient budget

Insufficient professional development

Insufficient administrative support

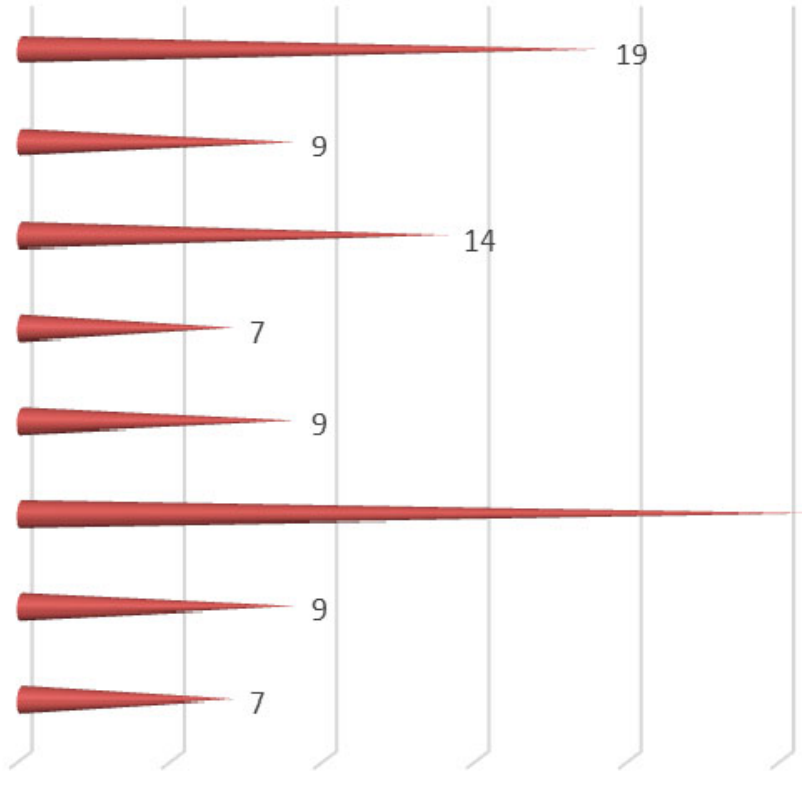

Figure 1.8 Challenges facing library

Other challenges cited during the interview included lack of proactiveness in identifying users with SNE, updating of technology, lack of direct communication with SNE users and lack of continuous collaboration with 
relevant departments.

5.4 Feelings and experiences of users with special needs on services provided by Post-Modern library Users with special needs were asked to identify services they enjoyed while in PML. Informants said they enjoyed the service in Table1.2 when in the postmodern library.

Table 1.2 Types of services enjoyed by informants in postmodern library

\begin{tabular}{ll}
\hline Types of service enjoyed in postmodern library & Percentage \\
\hline Availability of enough computers & 40 \\
Getting reference materials from the shelves & 20 \\
Sign language & 20 \\
Library Staff assistance in getting materials from shelves & 20 \\
Total & $\mathbf{1 0 0}$ \\
\hline
\end{tabular}

The reasons that made the users happy while in the library were captured and presented in Table 1.3 below.

Table 1.3 Reasons for enjoying some services in postmodern library

\begin{tabular}{lc}
\hline Reasons for enjoying some services in postmodern library & Percentage \\
\hline Because one is able to communicate with the users & 33.3 \\
Because one is in a position to carry his/her academic research on the computer by use of internet & 33.3 \\
Because learners are able to access information on internet & 33.3 \\
Total & $\mathbf{1 0 0}$ \\
\hline
\end{tabular}

5.5 Ways of Improving Services Provided to Special Needs Users.

Special needs user informants and other informants suggested various ways presented in Table 1.4 for improving services provided by postmodern library to learners with special needs.

Table 1.4 Ways of improving service delivery to persons with SNE

\begin{tabular}{lc}
\hline Ways of improving services to persons with SNE & Percentage \\
\hline Train more staff to serve the special needs section of the shelves & 16 \\
Increase of the library budget to cater for inclusive education and related assistive technology & 12 \\
devices & 12 \\
Increase the number of qualified SNE experts & 4 \\
Provide a bigger screen for special needs students as the number is increasing & 4 \\
Motivating both staff and students & 4 \\
More training on assistive technology to be accorded to library staff & 4 \\
More staff should be trained on handling the special needs & 4 \\
Marketing and promotion of existing assistive technologies available at postmodern library & 8 \\
Make lessons and staff who belong to the physically challenged involving. Let communication on & 8 \\
various privileges that they ought to enjoy to communicate to them & 4 \\
Increase the number of computers for users with special needs & 4 \\
Increase the number of CCTV for learners with low vision & 4 \\
Increase the budget allocation in order to purchase more equipment and employment of staff & 4 \\
members & 4 \\
Having a large space to accommodate more learners with special needs & 4 \\
Enlargement of the room or more rooms with facilities and resources needed by special needs users & 4 \\
Create space for learners with wheel chairs & 4 \\
Create more awareness of the need for inclusive education among the university community & 4 \\
Braille note takers are needed to make learning easier & 4 \\
Total &
\end{tabular}

\subsection{Recommendation}

The study recommends greater collaboration with other stakeholders in acquisition and training, and the identification of SNE users. In addition, marketing of SNE library services to university fraternity as well as increase in library budget are relevant concerns. There is also the need to train or deploy more staff in provision of various specialized information literacy services. The library should work with faculties and Admissions department to help identify users with special needs at the point of admissions or as an ongoing concern to prepare their services and resources in advance. To ensure there is adequate collaboration with these special needs users as is true to all users, librarians should apply the three A's approach of marketing namely: Attract through creation of incentives, Assist by being helpful and engaging with users and finally Affiliate through mobilization of third parties including other customers 


\section{References}

Edwards, R., Armstrong, P., \& Miller, N. (2001). Include me out: critical readings of social exclusion, social inclusion and lifelong learning. International Journal of Lifelong Education, 20(5), 417-428.

European Agency for Special Needs and Inclusive Education. (2015). Agency position on inclusive education systems.

Gianino, M. (2012). UNH Partnering on National Technical Assistance Center for Inclusive Education.

Kenya, L. O. (2013). The Constitution of Kenya: 2010. Chief Registrar of the Judiciary.

MacKay, D. (2006). The United Nations Convention on the rights of persons with disabilities. Syracuse J. Int'l L. \& Com., 34, 323.

Suleymanov, F. (2015). Issues of inclusive education: Some aspects to be considered. Electronic Journal for Inclusive Education, 3(4), 8

Thomas, G., \& Vaughan, M. (2004). Inclusive Education: Readings and Reflections. Inclusive Education. Open University Press. The McGraw-Hill companies, Order Services, PO Box 182605, Columbus, OH 432182605.

UNESCO. (2000). The Dakar Framework for Action Adopted a World Declaration on Education for All (EFA).

UNESCO, I. (2008, November). Inclusive education: The way of the future. In Conclusions and recommendations of the 48th session of the International Conference on Education (ICE), (págs. 25- 28). Geneva.

Virkus, S., \& Metsar, S. (2004). General introduction to the role of the library for university education. Liber Quarterly, 14(3/4).

World Conference on Education for All, \& Meeting Basic Learning Needs. (1990). World Declaration on Education for All and Framework for Action to Meet Basic Learning Needs. Inter-Agency Commission. 